\title{
EFEKTIFITAS MODUL PROGRAM LINEAR DALAM MENINGKATKAN PRESTASI BELAJAR MATEMATIKA
}

\author{
Ahmadi1, M. Shaefur Rokhman² \\ 1,2Program Studi Pendidikan Matematika FKIP UPS Tegal \\ Email: ahmadi_ak@yahoo.com
}

Dikirim: 2 Desember 2017; Diterima: 2 Januari 2018; Dipublikasikan: 31 Maret 2018

\begin{abstract}
ABSTRAK
Penelitian ini bertujuan untuk mengetahui apakah modul hasil pengembangan itu valid, untuk mengetahui apakah modul hasil pengembangan efektif dalam meningkatkan hasil belajar mahasiswa. Penelitian ini merupakan penelitian pengembangan. Pengumpulan data yang digunakan dengan cara validasi, observasi, angket, wawancara dan tes. Untuk mengetahui kevalidan modul Program Linear dilakukan dengan lembar validasi. Obvervasi, angket dan wawancara dilakukan untuk mengetahui kepraktisan pengembangan modul Program Linear. Modul hasil pengembangan dapat dikatakan cukup valid karena sudah memenuhi kriteria-kriteria modul yang baik, modul hasil pengembangan memenuhi kriteria kepraktisan karena mahasiswa memberikan penilaian melalui angket dengan skor yang cukup baik, berdasarkan hasil uji proporsi maupun uji-t dapat disimpulkan bahwa modul hasil pengembangan dalam penelitian ini dapat dikatakan efektif dalam meningkatkan hasil belajar mahasiswa.
\end{abstract}

Kata Kunci : Program Linear, Modul, Matematika 


\section{PENDAHULUAN}

Program Linear merupakan salah satu mata kuliah wajib yang dipelajari oleh mahasiswa Program Studi Pendidikan Matematika Universitas Pancasakti Tegal dengan bobot 3 SKS. Berdasarkan pengalaman peneliti, dalam perkuliahan Program Linear ada kecenderungan mahasiswa kurang aktif sehingga ruh dalam proses pembelajaran seakan - akan tidak ada dan mahasiswa cenderung mengikuti langkah-langkah penyelesaian yang sudah digariskan dosen. Hal ini mungkin dikarenakan kemampuan mahasiswa dalam membuat model matematis masih rendah. Salah satu hal yang menyebabkan rendahnya kemampuan membuat model matematis adalah terbatasnya bahan ajar yang sesuai dengan kemampuan mahasiswa.

Salah satu upaya yang bisa dilakukan agar kemampuan membuat model matematis semakin meningkat pada mata kuliah Program Linear adalah dengan mengembangkan bahan ajar yang berbasis realistik yang sesuai dengan kondisi mahasiswa. Tujuan pengembangan bahan ajar ini adalah agar mahasiswa merasakan kemudahan dalam mempelajari mata kuliah Program Linear sehingga tujuan dari mata kuliah ini dapat tercapai.

Berdasarkan permasalahan tersebut maka perlu dilakukan penelitian tentang "Efektifitas Modul Program Linear Dalam Meningkatkan Kemampuan Representasi Matematis".

Berdasarkan uraian di atas dapat dirumuskan suatu permasalahan sebagai berikut yaitu apakah Modul hasil pengembangan telah memenuhi standar isi, dan apakah Modul hasil pengembangan efektif meningkatkan prestasi belajar matematika.

Tujuan penelitian ini adalah sebagai berikut yaitu untuk mengetahui apakah modul hasil pengembangan telah memenuhi standar isi, dan untuk mengetahui apakah modul hasil pengembangan efektif dalam meningkatkan prestasi belajar matematika.

\section{METODE PENELITIAN}

Menurut Samsudi (2005: 105) langkah-langkah dalam penelitian adalah sebagai berikut :

1. Pengumpulan informasi

Tahap ini dilakukan guna melihat gambaran kondisi di lapangan yang berkaitan dengan proses belajar mengajar Program Linear di Universitas Pancasakti Tegal, kemudian menganalisis permasalahan. Proses yang dilakukan adalah sebagai berikut:

a. Menganalisis buku-buku teks Program Linear untuk melihat kesesuaian isi buku dengan standar kompetensi dan kompetensi dasar yang harus dicapai mahasiswa.

b. Melakukan wawancara terhadap mahasiswa mengenai hambatan atau problematika dalam memahami dan menguasai materi Program Linear.

c. Mereview buku-buku yang digunakan dalam pengembangan bahan ajar, khususnya tentang modul.

2. Tahap perancangan (design)

Pada tahapan ini, peneliti melakukan hal-hal sebagai berikut :

a. Membagi modul dalam beberapa bab yaitu bab 1 tentang sejarah program linear, bab 2 tentang konsep dasar program linear, bab 3 tentang Metode Grafik, bab 4 tentang metode simpleks, bab 5 tentang metode simpleks yang direvisi, dan bab 6 tentang analisis sensitivitas.

b. Masing-masing modul berisi standar kompetensi, kompetensi dasar, tujuan pembelajaran, kegiatan belajar(uraian dan contoh, latihan, rangkuman, tes formatif, umpan balik), kunci jawaban.

3. Tahap pengembangan bentuk awal produk

Setelah desain selesai dirancang kemudian dilakukan tahap validasi yaitu:

a. validitas isi,digunakan untuk mengecek kesesuaian antara modul dengan silabus mata kuliah. 
b. validitas konstruk, digunakan untuk mengecek kesesuaian antara komponen modul dengan indikator yang telah ditetapkan.

Tabel 1. Aspek Validasi Modul

\begin{tabular}{ll}
\hline No & Aspek \\
\hline 1 & Tujuan \\
2 & Rasional \\
3 & Isi modul \\
4 & Karakteristik modul \\
5 & Kesesuaian \\
6 & Bahasa \\
7 & Bentuk fisik \\
8 & Keluwesan \\
\hline Sumber : Samsudi (2005)
\end{tabular}

4. Tahap uji lapangan dan revisi produk

Pada tahap ini dilakukan revisi pada modul, kemudian dilakukan uji coba produk untuk mengetahui tingkat praktikalitas dan efektifitas. Uji coba dilakukan dalam pembelajaran Program Linear mahasiswa pendidikan matematika semester III.B Universitas Pancasakti Tegal. Untuk mengetahui tingkat efektifitas produk yang telah dikembangkan dapat dilihat dari aktifitas dan hasil belajar mahasiswa. Tingkat praktikalitas modul dapat kita ketahui dengan cara memberikan angket praktikalitas pada saat pembelajaran berlangsung.

5. Revisi produk akhir

Pada tahap ini dilakukan revisi produk sehingga sesuai dengan yang diharapkan.

Penelitian ini menggunakan instrumen berupa lembar validasi, lembar observasi, angket, dan pedoman wawancara.

1. Lembar validasi

Lembar validasi yang digunakan adalah lembar validasi modul, lembar validasi satuan acara perkuliahan, dan lembar validasi wawancara mahasiswa.

2. Lembar observasi

Lembar observasi dipakai untuk memperoleh informasi mengenai proses pembelajaran mahasiswa dengan menggunakan modul hasil pengembangan

3. Angket

Untuk mendapatkan data tentang kepraktisan modul hasil pengembangan digunakan instrumen angket.

4. Pedoman wawancara

Selain dengan instrumen angket, data tentang kepraktisan modul hasil pengembangan dapat diperoleh dengan wawancara.

5. Tes

Tes digunakan untuk menguji kemampuan representasi matematis mahasiswa mengenai Program Linear

Adapun teknik analisis data pada penelitian ini adalah :

1. Lembar validasi modul

Hasil validasi dari validator terhadap seluruh aspek yang dinilai, disajikan dalam bentuk tabel. Selanjutnya dicari rerata skor tersebut dengan menggunakan rumus

$$
R=\frac{\sum_{i=1}^{n} V_{i}}{n} \quad \text { (Sudjana 2002: 210) }
$$

Cara sitasi: Ahmadi, dan Rokhman, M. S. 2018. Efektifitas Modul Program Linear dalam Meningkatkan Prestasi Belajar Matematika. Teorema: Teori dan Riset Matematika Vol 2, No 2 (2018). Hal 117-128 
dengan:

$\mathrm{R}=$ rerata hasil penilaian dari para validator

$\mathrm{Vi}=$ skor hasil penilaian validator ke-i

$\mathrm{n}$ = banyak validator

rentangan skor antara 0 sampai dengan 4 . Berdasarkan rerata tersebut akan ditentukan kriteria interval kevalidan yaitu (1) tidak valid, (2) kurang valid, (3) cukup valid, (4) valid, (5) sangat valid

2. Kepraktisan penggunaan modul

Berdasarkan lembar observasi dan wawancara maka akan diperoleh deskripsi penggunaan modul. Sedangkan berdasarkan angket maka akan diperoleh prosentase kepraktisan penggunaan modul.

3. Keefektifan penggunaan modul

a. Uji Homogenitas

Uji homogenitas digunakan untuk mengetahui apakah kedua kelompok mempunyai varians yang sama atau tidak. Apabila kedua kelompok mempunyai varians yang sama maka kedua kelompok tersebut dikatakan homogen.

Adapun rumus yang digunakan adalah sebagai berikut:

$$
F=\frac{\text { Varians terbesar }}{\text { Varians terkecil }}
$$

Tolak $H_{0}$ jika $F \geq F_{1 / 2}$ a $(V 1, V 2) \quad$ (Sudjana 2002: 250).

b. Uji Normalitas

Uji Normalitas digunakan untuk pengujian normalitas sampel. Rumus yang digunakan adalah :

$$
\chi^{2}=\sum_{i=1}^{k} \frac{\left(f_{0}-f_{h}\right)^{2}}{f_{h}}
$$

Keterangan:

$f_{0}$ : frekuensi hasil pengamatan/ observasi

$f_{h}$ : frekuensi hasil yang diharapkan

Kriteria pengujian jika $\chi^{2}$ hitung $<X^{2}(1-a)(k-1)$ maka sampel diambil dari populasi yang berdistribusi normal (Sugiyono 2009: 241).

c. Uji ketuntasan belajar (individu)

Belajar dikatakan tuntas secara individu dengan memenuhi syarat ketuntasan belajar yaitu nilai prestasi belajar mahasiswa mencapai sekurang-kurangnya 56 atau $\mathrm{C}$.

d. Uji Ketuntasan Klasikal (Uji Proporsi)

Untuk menguji apakah tiap mahasiswa tuntas digunakan uji proporsi satu pihak.

Hipotesis statistik yang akan diuji adalah sebagai berikut.

$\mathrm{H}_{0}: \pi \geq 75 \%$ (proporsi mahasiswa yang mendapat nilai $\geq 56$ lebih besar dan sama dengan $75 \%)$

$\mathrm{H}_{1}: \quad \pi<75 \%$ (proporsi mahasiswa yang mendapat nilai $\geq 56$ lebih kecil dari $75 \%$ )

Rumus yang digunakan untuk menghitung ketuntasan belajar klasikal adalah sebagai berikut.

$$
z=\frac{\frac{x}{n}-\pi_{0}}{\sqrt{\frac{\pi_{0}\left(1-\pi_{0}\right)}{n}}}
$$

Cara sitasi: Ahmadi, dan Rokhman, M. S. 2018. Efektifitas Modul Program Linear dalam Meningkatkan Prestasi Belajar Matematika. Teorema: Teori dan Riset Matematika Vol 2, No 2 (2018). Hal 117-128 
$\mathrm{n}$ = banyaknya mahasiswa

$\pi_{0}=$ harga yang sudah diiketahui

$\mathrm{x}=$ nilai mahasiswa

dengan uji proporsi, tolak $\mathrm{H}_{0}$ jika $\mathrm{z} \leq-\mathrm{z}_{0,5(1-\alpha)}$, dimana $\mathrm{z}_{0,5(1-\alpha)}$ didapat dari daftar normal baku dengan peluang $0,5(1-\alpha)$ sedangkan dalam hal lainnya hipotesis $\mathrm{H}_{0}$ diterima (Sudjana 2002:234)

e. Uji beda dua rata-rata

Untuk mengetahui apakah ada perbedaan kemampuan representasi matematis peserta didik antara kelas uji coba pengembangan modul dengan kelas kontrol yang menggunakan metode konvensional kita gunakan uji beda dua rata-rata uji dua pihak.

Hipotesis:

$\mathrm{H}_{0}: \quad \mu_{1}=\mu_{2}$ (tidak ada perbedaan rata-rata kemampuan representasi matematis antara kelas uji coba modul dengan kelas kontrol).

$\mathrm{H}_{1}: \quad \mu_{1} \neq \mu_{2} \quad$ (ada perbedaan rata-rata kemampuan representasi matematis peserta didik kelas uji coba modul dengan rata-rata kemampuan representasi matematis peserta didik kelas kontrol).

Hipotesis diuji dengan kriteria:

1) Jika $\sigma_{1}=\sigma_{2}$ maka menggunakan persamaan sebagai berikut (Sudjana, 2002: 239).

$$
\begin{gathered}
t=\frac{\overline{x_{1}}-\overline{x_{2}}}{s \sqrt{\frac{1}{n_{1}}+\frac{1}{n_{2}}}} \\
s=\frac{\left(n_{1}-1\right) s_{1}{ }^{2}+\left(n_{2}-1\right) s_{2}{ }^{2}}{n_{1}+n_{2}-2}
\end{gathered}
$$

Jika $\mathrm{t} \geq t_{\left(1-\frac{1}{2} \alpha\right)}$ dengan taraf nyata $5 \%$ dan $\mathrm{dk}=\left(\mathrm{n}_{1}+\mathrm{n}_{2}\right)-2$ maka tolak $\mathrm{H}_{0}$.

2) Jika $\sigma_{1 \neq} \sigma_{2}$, maka menggunakan persamaan sebagai berikut (Sudjana, 2002: 239).

$$
t^{\prime}=\frac{\bar{x}_{1}-\bar{x}_{2}}{\sqrt{\left(s_{1}{ }^{2} / n_{1}\right)+\left(s_{2}{ }^{2} / n_{2}\right)}}
$$

Kriteria pengujian adalah terima $\mathrm{H}_{0}$ jika:

$$
-\frac{w_{1} t_{1}+w_{2} t_{2}}{w+w_{2}}<t^{\prime}<\frac{w_{1} t_{1}+w_{2} t_{2}}{w_{1}+w_{2}}
$$

Dengan : $w_{1}=s_{1}{ }^{2} / n_{1} ; w_{2}=s_{2} 2 / n_{2}$

$$
\mathrm{t}_{1}=t_{\left(1-\frac{1}{2} \alpha\right),\left(n_{1}-1\right)} \mathrm{dan}_{\mathrm{t}_{2}={ }_{\left(1-\frac{1}{2} \alpha\right),\left(n_{2}-1\right)}}
$$

Untuk mengetahui peningkatan kemampuan representasi matematis masing-masing peserta didik berdasarkan pretest dan posttest menggunakan persamaan sebagai berikut.

$$
(\mathrm{g})=\frac{\text { skor post test-skor pretest }}{\text { skor maksimal-skor pretest }}
$$


Kriteria perolehan Normalitas Gain (g) dapat dilihat pada Tabel 4 berikut.

Tabel 4. Kriteria Perolehan Normalitas Gain (g)

\begin{tabular}{ll}
\hline $\mathrm{g})$ & Keterangan \\
\hline $\mathrm{g})<0,30$ & Rendah \\
$\mathrm{J}, 30 \leq(\mathrm{g})<0,70$ & Jedang \\
$\mathrm{J}, 70 \geq(\mathrm{g})$ & Tinggi
\end{tabular}

\section{HASIL DAN PEMBAHASAN}

1. Hasil penelitian

Tabel 2. Ringkasan hasil validasi modul

\begin{tabular}{|c|c|c|c|c|c|c|}
\hline \multirow[t]{2}{*}{ No } & \multirow{2}{*}{ Indikator } & \multicolumn{3}{|c|}{$\begin{array}{l}\text { Nilai } \\
\text { Validator }\end{array}$} & \multirow{2}{*}{$\begin{array}{l}\text { Rata } \\
\text { rata }\end{array}$} & \multirow{2}{*}{ Ket } \\
\hline & & & $\|$ & III & & \\
\hline 1 & Identitas & 4 & 3 & 3 & 3,33 & Valid \\
\hline 2 & $\begin{array}{l}\text { Standar kopetensi dan } \\
\text { kompetensi dasar }\end{array}$ & 3 & 3 & 4 & 3,67 & Valid \\
\hline 3 & $\begin{array}{l}\text { Kesesuaian tujuan } \\
\text { pembelajaran dg standar } \\
\text { kompetensi dan kompetensi } \\
\text { dasar }\end{array}$ & 3 & 3 & 3 & 3 & Valid \\
\hline 4 & $\begin{array}{l}\text { Tujuan pembelajaran } \\
\text { mendudkung standar } \\
\text { kompetensi dan kompetensi } \\
\text { dasar }\end{array}$ & 3 & 3 & 4 & 3 & Valid \\
\hline 5 & $\begin{array}{l}\text { Penjabaran tujuan } \\
\text { memenuhi unsure problem } \\
\text { solving }\end{array}$ & 3 & 2 & 3 & 2,66 & $\begin{array}{l}\text { Cukup } \\
\text { Valid }\end{array}$ \\
\hline 6 & $\begin{array}{l}\text { Indikator pencapaian } \\
\text { standar kopetensi dan } \\
\text { kopetensi dasar }\end{array}$ & 3 & 4 & 3 & 3,33 & Valid \\
\hline 7 & $\begin{array}{l}\text { Memuat materi yang sesuai } \\
\text { dengan standar kompetensi } \\
\text { dan kompetensi dasar }\end{array}$ & 4 & 3 & 3 & 3,33 & Valid \\
\hline 8 & $\begin{array}{l}\text { Peta konsep telah dijabarkan } \\
\text { dengan baik }\end{array}$ & 3 & 2 & 2 & 2,33 & $\begin{array}{l}\text { Cukup } \\
\text { Valid }\end{array}$ \\
\hline 9 & $\begin{array}{l}\text { Kesesuaian isi dengan } \\
\text { tujuan pembelajaran }\end{array}$ & 3 & 4 & 3 & 3,33 & Valid \\
\hline 10 & Kebenaran konsep & 3 & 4 & 2 & 3 & Valid \\
\hline 11 & Urutan konsep & 4 & 3 & 3 & 3,33 & Valid \\
\hline 12 & $\begin{array}{l}\text { Keterbacaan atau Bahasa } \\
\text { modul }\end{array}$ & 4 & 3 & 3 & 3,33 & Valid \\
\hline 13 & $\begin{array}{l}\text { Komponen kegrafisan dalam } \\
\text { modul }\end{array}$ & 3 & 2 & 2 & 2,33 & $\begin{array}{l}\text { Cukup } \\
\text { Valid }\end{array}$ \\
\hline 14 & $\begin{array}{l}\text { Pemanfaatan bahasa secara } \\
\text { efektif dan Efisien }\end{array}$ & 4 & 3 & 3 & 3,33 & Valid \\
\hline 15 & $\begin{array}{l}\text { Kelengkapan modul sebagai } \\
\text { bahan ajar }\end{array}$ & 3 & 2 & 3 & 2,67 & $\begin{array}{l}\text { Cukup } \\
\text { Valid }\end{array}$ \\
\hline
\end{tabular}

Cara sitasi: Ahmadi, dan Rokhman, M. S. 2018. Efektifitas Modul Program Linear dalam Meningkatkan Prestasi Belajar Matematika. Teorema: Teori dan Riset Matematika Vol 2, No 2 (2018). Hal 117-128 
Dari tabel tersebut dapat dilihat bahwa validator secara umum memberikan penilaian diatas nilai 2 untuk semua indikator sehingga dari tiga validator menyatakan kelimabelas indikator untuk modul hasil pengembangan semuanya berkriteria cukup valid sampai valid. Sehingga dapat dikatakan bahwa modul hasil pengembangan telah memenuhi standar isi

Tabel 3. Deskripsi Data Prestasi Belajar Matematika Kelas Eksperimen dan Kelas Kontrol

\begin{tabular}{llcc}
\hline No & Ukuran & Kelas Eksperimen & Kelas Kontrol \\
\hline 1 & Mean & 72,9032 & 66,4516 \\
2 & Median & 70 & 65 \\
3 & Modus & 70 & 70 \\
4 & Standar Deviasi & 10,3902 & 12,4628 \\
5 & Varian & 107,957 & 155,323 \\
6 & Max & 95 & 95 \\
7 & Min & 50 & 45 \\
\hline
\end{tabular}

Dari tabel di atas dapat dilihat bahwa nilai rata-rata prestasi belajar matematika pada kelas eksperimen lebih besar dari pada kelas kontrol, meskipun memiliki modus yang sama yaitu 70 .

\section{Pembahasan}

Modul hasil pengembangan dalam penelitian ini sudah memuat unsur-unsur yang menjadi karakteristik suatu pembelajaran yang dianggap baik oleh beberapa dosen ahli yang memang kompeten dalam masalah ini. Modul yang dikembangkan sudah memuat unsur identitas, petunjuk umum yaitu kompetensi dasar, pokok bahasan, indikator pencapaian, referensi, strategi pembelajaran, lembar kegiatan pembelajaran, petunjuk bagi mahasiswa, dan evaluasi, kemudian isi modul atau materi modul yang tidak berbeda dengan kompetensi dasar, peta konsep yang dijabarkan dengan begitu baik. Selain itu dari segi bahasa modul ini dapat dikatakan efektif dan efisien serta kelengkapan modul sesuai dengan tujuan penelitian pengembangan.

Pernyataan tersebut di atas sejalan dengan penilaian yang dilakukan oleh tim validator, dimana nilai rata-rata total dari tim validator dari setiap aspek pada modul adalah 3,23 . Nilai ini menunjukkan bahwa secara keseluruhan modul ini berkriteria cukup valid, sehingga cukup layak dipakai dalam pembelajaran dalam suatu acara perkuliahan.

Tidak semua indikator dilakukan revisi, hanya beberapa bagian yang mendapat perhatian Tim Validator. Pembahasan contoh soal yang dirasakan kurang mudah dipahami mahasiswa karena ada beberapa langkah perhitungan yang dilewatkan, direvisi dengan melengkapi langkah-langkah penyelesaian sehingga mahasiswa dapat memahami penyelesaian contoh soal tersebut meskipun dosen tidak menjelaskan lagi permbahasan soal contoh ini. Masukan lain berkaitan dengan soal latihan. Revisi revisi lainnya terkait dengan masukan Tim Validator adalah karena kesalahan penulisan dalam pengetikan. Meskipun banyak revisi sudah dilakukan akan tetapi karena keterbatasan jumlah Tim Validator sangat memungkinkan bila dalam perjalanannya nanti diketahui ada kekurangan yang baru diketahui kemudian, namun secara keseluruhan modul ini cukup valid dan sudah memenuhi standar isi.

Hasil penelitian diperoleh bahwa prestasi belajar matematika berdasarkan hasil dari uji proporsi satu pihak kanan pada kelas eksperimen mencapai target yaitu prestasi belajar matematika pada kelas tersebut yang mencapai KKM (70) sebesar 83,9\% sehingga dapat dikatakan kelas tersebut tuntas. Berdasarkan uji t pasangan diperoleh thitung $\neq$ tabel yaitu 7,888 $\neq 2,05$ sehingga ada perbedaan prestasi belajar matematika antara kelas eksperimen dan kelas kontrol. 
Selain itu, berdasarkan uji t pihak kanan diperoleh thitung $>t_{\text {tabel }}$ yaitu 2,214 $>$ 1,699 sehingga prestasi belajar matematika kelas eksperimen lebih baik dari kelas kontrol. Sehingga, dapat dikatakan bahwa modul hasil pengembangan efektif dalam meningkatkan prestasi belajar matematika.

\section{KESIMPULAN}

Secara umum dapat dikatakan modul ini cukup valid karena sudah memenuhi kriteria-kriteria modul yang baik, mahasiswa dapat mengambil manfaat dari modul ini, karena mereka tidak lagi konsentrasi untuk mencatat apa yang dijelaskan dosen karena penjelasan yang ada dalam modul sudah dapat langsung dipahami oleh mahasiswa, dan berdasarkan hasil uji proporsi maupun uji $t$ dapat disimpulkan bahwa modul yang dikembangkan dalam penelitian ini dapat dikatakan efektif dalam meningkatkan hasil belajar

\section{REKOMENDASI}

1. Membuat bahan ajar merupakan bagian dari tugas seorang dosen, oleh karena itu berusahalah untuk membuatnya.

2. Dari hasil membuat modul bisa dibuat sebuah penelitian yang dapat memperkaya khasanah berpikir kita

\section{UCAPAN TERIMA KASIH}

1. Ristekdikti yang telah mendanai penelitian ini.

2. Dosen program studi pendidikan matematika FKIP UPS Tegal yang selalu memberi inspirasi dalam hal menulis dan penelitian.

3. Istri tercinta yang senantiasa mendorong untuk berkarya untuk bangsa, negara, dan agama.

\section{DAFTAR PUSTAKA}

Samsudi. (2005). Desain Penelitian Pendidikan. Semarang: UNNES.

Sudjana. (2002). Metode Statistika. Bandung: Tarsito.

Sugiyono, (2009). Metode Penelitian Pendidikan pendekatan Kuantitatif, Kualitatif, dan $R \& D$. Bandung: Alfabeta. 